\title{
Palco e bastidores da Conferência Internacional sobre População e Desenvolvimento
}

\author{
Donald Sawyer
}

\section{Introdução}

Em setembro de 1994, como um dos representantes da Associação Brasileira de Estudos Populacionais (Abep), fiz parte da delegação brasileira oficial na Conferência Internacional sobre População e Desenvolvimento (CIPD) no Cairo. Em abril, tinha participado na mesma qualidade do III Comitê Preparatório (Prepcom III) na sede das Nações Unidas (ONU), em New York. Nos anos 1990, a CIPD fez parte de um ciclo de conferências da ONU, incluindo meio ambiente, direitos humanos, desenvolvimento social, mulheres, habitação, entre outros.

Além de conhecer o que transcorreu tanto no palco quanto nos bastidores e contribuir para a redação de diversos trechos do Programa de Ação, aprendi algumas lições. Este relato sobre os pontos principais da CIPD pretende subsidiar desdobramentos futuros dessas questões delicadas e polêmicas. Conhecer o que aconteceu há 25 anos pode ajudar a evitar retrocessos e alcançar novos avanços. Os debates oficiais, nos palcos, estão registrados nos números diários do Earth Negotiations Bulletin, enquanto o presente ponto de vista inclui informações sobre os bastidores.

\footnotetext{
* Instituto Sociedade, População e Natureza (ISPN), Brasília-DF, Brasil (don@ispn.org.br; https://orcid.org/0000-00018870-6566).
} 


\section{Belo Horizonte a Cairo}

No voo de Brasília a New York, conversei com Paulo de Tarso Flecha Lima, embaixador do Brasil em Washington. Comentei que o Itamaraty tinha feito um trabalho interessante com as ONGs. Também relatei minha conversa com Tim Wirth, o ex-senador que liderava a delegação americana no Prepcom, quando pedi ajuda para evitar linguagem no Programa de Ação que pudesse excluir a América Latina dos recursos internacionais. Ele reagiu dizendo que o Brasil não precisava de recursos para população devido à queda vertiginosa da fecundidade. Por outro lado, esta visão poderia implicar escassez de recursos para programas públicos ou privados importantes.

No voo para o Cairo, um padre e professor de Catholics for a Free Choice, que conhecia bem o Vaticano, me explicou que, embora a linguagem oficial fosse de dogma e princípios, o que realmente interessava era o jogo de poder.

No Hotel Movenpick, Germán Bravo, do Fundo de População das Nações Unidas (UNFPA), me deu um briefing informal: para os árabes, "saúde sexual" soava mal e "outras uniões" admitiam tudo, fosse hétero ou homo. A opinião da universidade islâmica Al Azhar contra o documento foi muito forte.

Diversos jornalistas brasileiros queriam me entrevistar. Entretanto, tínhamos recebido instruções firmes de não conversar com a imprensa sobre os assuntos em negociação. Assim, apenas forneci algum background sobre o que estava em jogo.

Os porta-vozes oficiais da missão brasileira eram Leonor Franco, ministra da Ação Social, e o embaixador Geraldo Holanda. Ele substituiu o embaixador Mauro Couto, chefe da missão no Prepcom, por causa de reclamações do Vaticano, o primeiro capítulo de uma tragédia que poucos conhecem.

No domingo, com meu crachá de "Del. Staff”, fui para o Centro de Convenções, onde a delegação brasileira tinha três salas. Não contava com uma televisão para acompanhar a plenária, o que teria custado US\$2.500.

Numa reunião da delegação, recebemos as instruções confidenciais preparadas pelo Itamaraty e combinamos uma escala de participação nas sessões por capítulo e nas plenárias. Também havia reuniões informais. 0 objetivo era remover os colchetes nas palavras sobre as quais ainda não havia consenso.

\section{Primeiros dias da Conferência}

Durante a abertura oficial na segunda-feira, dia 5, trabalhei com o chefe de gabinete da ministra na revisão da tradução ao inglês do seu discurso, enxugando ao máximo por causa do limite de tempo de apenas dez minutos.

Esclarecemos os ataques que a advogada de direitos humanos Herilda Balduino, chefe oficial da delegação brasileira, lançou contra a posição do governo brasileiro numa audiência pública na Câmara dos Deputados. 
Na delegação americana, encontrei Nils Daulaire, meu colega de Harvard, que era assessor sênior para população e saúde na United States Agency for International Development (USAID) no governo Clinton. Estávamos afinados em praticamente tudo, como aborto raro e seguro.

Uma vez que o embaixador Mauro Couto não podia, fui participar de uma reunião entre o G-77 (grupo de países em desenvolvimento) e o G-7 (países desenvolvidos). Deixando claro que eu participava como Brasil, sem poder falar em nome do G-77 e China, expliquei algumas preocupações do mundo em desenvolvimento. 0 objetivo da discussão era os recursos previstos. Entre outras coisas, eu disse que estávamos preocupados com os custos atualizados, especialmente para populações ainda não atendidas, e os montantes previstos para HIV/Aids.

No Fórum de ONGs, vi Tom Merrick, do Banco Mundial, que foi professor visitante pela Fundação Ford no Centro de Desenvolvimento e Planejamento Regional (Cedeplar) da Universidade Federal de Minas Gerais entre 1971 e 1974, iniciando o programa de mestrado que, na década seguinte, transformamos no primeiro doutorado em Demografia na América Latina.

Deise Kusztra e Cláudia Valadão participaram, pela Agência Brasileira de Cooperação (ABC), do Program Review and Strategy Development (PRSD) do UNFPA no Brasil em 1991. Deise me emprestou uma bandeira brasileira para colocar no escritório da delegação.

Fui ouvir o discurso de Al Gore, vice-presidente dos Estados Unidos, que também foi meu colega em Harvard. A última vez que o tinha visto foi em 1992, quando levei Fábio Feldmann, o deputado verde, para almoçar com ele, o green senator, no Riocentro. Dessa vez não deu para encontrar. Ele estava abatido por causa dos ataques do Vaticano.

No coquetel do dia 7 de setembro, na residência do embaixador brasileiro no Cairo, encontrei José Alberto Magno de Carvalho, que foi nosso diretor do Cedeplar. Ele estava cuidando da série de palestras de especialistas da International Union for the Scientific Study of Population (IUSSP), que ele chegou a presidir, no Fórum de ONGs.

\section{Religião}

No Prepcom, um representante do Vaticano (Estado membro da ONU) havia me explicado a objeção a "direitos sexuais" porque sugere que um homem pode obrigar uma mulher a fazer sexo com ele invocando seu direito humano. Como seriam os direitos sexuais para o celibato de padres e freiras?

"Outras uniões" foi uma das frases mais difíceis, porque sugeria relações sexuais fora do casamento heterossexual. Os caribenhos insistiam na necessidade, porque apenas uma minoria naquela região formalizava o casamento. Alguns países já permitiam o casamento entre pessoas do mesmo sexo. No fim, tivemos que tirar tanto o casamento quanto as outras uniões. 0 texto ficou meio sem sentido, mas foi aprovado sem restringir-se ao casamento.

Me perguntei onde estava a secularização que meu mestre Gino Germani definiu como um dos três elementos da modernização. Há que se relativizar a secularização. 0 
fundamentalismo cresceu. Em todos os continentes, a religião continua forte, inclusive como Estado representado na ONU.

Entre os muçulmanos, pessoas como Benazir Bhutto, que eu conhecia em Harvard, tinha a enorme vantagem de conhecer profundamente tanto o Oriente quanto o Ocidente, enquanto os ocidentais conhecem o Oriente apenas superficialmente. No seu discurso no Cairo, feito como muçulmana, esposa e mãe, Benazir se colocou como "fiscal” do documento para que não contrariasse o Islã. Funcionou perfeitamente.

\section{Reprodução}

0 “Grupo do 7" - isto é, do capítulo 7, sobre Direitos Reprodutivos e Saúde Reprodutiva, não o G-7 - reunia-se numa salinha onde os representantes do Irã, do Paquistão e do Egito ficaram de um lado e os do Vaticano, do outro, com os Estados Unidos, Canadá e Brasil no meio. Elza Berquó, Jacqueline Pitanguy e Sonia Corrêa acompanharam de perto. A mudança de "demographic policies" para "population-related policies" foi contribuição da Sonia Corrêa.

Um colombiano coordenou o grupo. Embora houvesse reclamação das mulheres do Norte e do Brasil que ele estava dando muita atenção aos muçulmanos, foi uma escolha perfeita em termos diplomáticos. Eu ajudei na redação em inglês, evitando alguns erros crassos. Os argentinos elogiariam meu inglês, "quase sem sotaque".

Adrienne Germain, assessora da delegação americana sobre saúde da mulher, propôs a retirada da definição de saúde sexual, subsumindo o conceito dentro da saúde reprodutiva. Isto permitiria retirar os colchetes das palavras saúde sexual que apareciam cerca de cem vezes no documento.

Os três países islâmicos apresentaram diversas emendas. Queriam acrescentar a palavra "normal" na frase "safe and satisfying sex life". As outras emendas não modificavam significativamente o sentido. Queriam "relevant services" no caso de adolescentes ou crianças, "all users" em vez de "men, women and adolescent users". Tudo bem. A grande solução, contudo, foi puxar o chapeau do capítulo 2 para o primeiro parágrafo do capítulo 7. A soberania nacional, que já tentamos usar em New York, resolveu o problema do aborto. No final, resolvemos todas as pendências do capítulo.

A representante da África do Sul, principiante na ONU depois do fim do Apartheid, queria reforçar a linguagem sobre os direitos, deixando mais claro que a segurança das pessoas referia-se a pessoas já nascidas. Depois ajudei a elaborar: "All human beings are born free and equal with dignity and have the right to life, liberty and security of the person."

O não alinhamento do Brasil, maior país católico do mundo, com a Santa Sé sobre aborto e adolescentes deve ter contribuído para sua decisão de não obstruir o consenso de uma conferência internacional sobre população. 


\section{Soberania, direitos humanos e religião}

No dia 9, avançaram as discussões sobre o chapeau do capítulo sobre princípios. Parecia mera formalidade, mas tínhamos que colocar a soberania, os direitos humanos e a religião nos seus devidos lugares. Soberania e direitos são sagrados, mas religião era problemática. O Reino Unido introduziu valores éticos. No grupo de Amigos do Chairman, inserimos "due" antes de "respect for religious and ethical values" para relativizar.

A negociação já estava fechada quando o ministro plenipotenciário egípcio Suliman Awaad entrou na sala. Eles não podiam aceitar "due respect" e nos imploraram uma expressão mais forte. Fizeram o gesto de cortar o pescoço para dizer o que aconteceria se 0 documento saísse desse jeito. Os fundamentalistas já estavam matando turistas no sul do Egito. Assim, concordamos com "full respect", mas consegui inserir "the various" antes de "religious and ethical values" para garantir o Estado laico, algo defendido por meus ancestrais desde o século XVI.

Às nove e meia da noite de sábado, na reunião sobre o chapeau, o embaixador norueguês levou em conta apenas o texto que a Europa combinou com o Egito. Quando o grupo pediu para listar as diferenças, ele omitiu a mais importante: a supressão das minhas palavras "the various". Ao mesmo tempo, provavelmente por incompetência, o G-77 não reclamou.

Mais uma vez, eu me encontrava representando o Brasil como se fosse o menino holandês com o dedo no buraco no dique prestes a estourar. Sem as palavras "the various", poderia haver pleno respeito para uma única religião de Estado e especificamente para a Sharia, a lei muçulmana totalmente incompatível com o que estava sendo proposto. Tentei explicar o problema para outros delegados, mas ninguém parecia entender. Preocupadíssimo, achei que minhas palavras "full respect", sem a diversidade, acabariam sendo um completo retrocesso nos direitos humanos, especialmente das mulheres. Aí sim poderia ser justificada até mesmo a mutilação genital feminina, por culpa minha.

Não consegui dormir me dando conta do que realmente estava acontecendo. Não se tratava de incompetência. Os europeus, os mais preocupados com os direitos humanos, não teriam aceito o texto sobre pleno respeito para a religião sem qualificações se não tivessem sofrido alguma pressão muito forte.

No domingo, dia 11 de setembro, liguei para a representante americana, que não tinha percebido as manobras. Nunca na minha vida imaginei ligar para a Casa Branca. Ela entendeu tudo e disse que os Estados Unidos teriam reuniões com Egito e Europa ainda naquele dia.

Conversei com diversas pessoas no hotel, incluindo William Waack, que na época era correspondente da Veja em Berlim. Eu achava que estávamos brincando com o começo da Terceira Guerra Mundial.

À tarde, fui chamado para uma conversa com Joseph Chamie, deputy secretary general da Conferência. Ele disse que o Egito havia pressionado a Europa, conforme eu imaginava. Estava em jogo, no mínimo, o Canal de Suez, que poderia cair nas mãos de fundamentalistas. 
Se o Egito caísse, também cairiam a Argélia e a Jordânia. Acabaria o equilíbrio de poder no Oriente Médio. As intervenções militares da Otan e os fluxos de refugiados implicariam custos impensáveis.

Na segunda-feira, dia 12, encontrei Suliman Awaad na minha frente na fila no Centro de Convenções. Perguntei: "Suliman, o que aconteceu, as palavras 'the various' sumiram?” Ele respondeu: “não tem problema. A Índia quer. Nós não gostamos, mas podemos aceitar". Uau!

Quando encontrei os delegados americanos, ficou claro que o Egito se tornou mais flexível depois da reunião com os Estados Unidos no dia anterior. Fiquei tremendamente aliviado, mas ainda um pouco assustado com os meios utilizados para se chegar a este fim e meu papel pessoal nisso.

\section{Migração internacional}

Sem chamar muita atenção, a migração internacional foi um assunto mais complicado do que aborto ou outras uniões, encontrando grande resistência entre os países europeus. Os países desenvolvidos não queriam escancarar as portas. Tratava-se em parte de racismo e preconceito, mas também havia fundamentos econômicos e políticos objetivos com respeito a quem pagou as contas para gerar os benefícios. Discutimos a conveniência de uma conferência específica, mas foi considerada pouco viável.

Em função dessa resistência, o princípio sobre migrantes foi mudado para se referir a migrantes documentados. Quando Cuba inseriu uma frase referindo-se aos migrantes em geral usando as palavras "the migrants", consegui colocar "all" em vez de "the" nos dois lugares, para que a frase garantisse todos os direitos humanos para todos os migrantes.

\section{Plenária final}

Alguns representantes americanos e britânicos, que na prática lideravam a delegação europeia, estavam preocupados com possíveis surpresas de última hora. Em cinco minutos, três pessoas da delegação americana me procuraram para saber "What's the poop?", achando que "Don will know". Eu não sabia, mas tentei me informar.

Joseph Van Arendonk, do UNFPA, estava preocupado com a implementação do Programa de Ação. Para ele, a Conferência Rio-92 foi um desastre para população. Expliquei que população foi deixada para deliberação no Cairo para não atrapalhar o consenso no Rio de Janeiro sobre o desenvolvimento sustentável.

Gro Harlem Brundtland comentou que o tema populacional não recebeu o tratamento devido em seu relatório Nosso futuro comum, que define o desenvolvimento sustentável. Ela disse que a resistência foi do Brasil. Foi de algum membro da comissão internacional, ou de uma consulta realizada no Brasil? 
Na sessão de encerramento, percebi que tinha escapado do nosso filtro a frase malthusiana "population, poverty, production and consumption and other threats to the environment". Consultei a Argélia (que representava o G-77), o Reino Unido, os Estados Unidos, a Suécia e a Áustria e consegui mudar a linguagem do documento depois de sua aprovação na plenária final.

Na saída, fui entrevistado pela rádio do Egito. Depois que as negociações acabaram, eu disse que o verdadeiro trabalho estava apenas começando, com a necessidade de implementação da linguagem bonita, traduzindo o discurso para a prática.

Por causa de sua atuação de apoio ao Programa de Ação, o Brasil poderia, ironicamente, perder em vez de ganhar recursos internacionais. Poderia ser "taken for granted" enquanto se canalizavam recursos para a América Central, por exemplo. Por outro lado, o Brasil merece investimentos de cooperação internacional na medida em que pode mostrar liderança e influenciar outros países.

No voo de volta a New York, li no jornal sobre grandes doações dos Estados Unidos às universidades egípcias. Este tipo de jogo de poder nos bastidores pode explicar decisões tomadas no palco. Depois soube que também foi estabelecida uma parceria binacional sobre desenvolvimento econômico e ciência e tecnologia.

Contudo, fiquei com dúvida se a frase sobre pleno respeito a valores religiosos poderia sair pela culatra, justificando, por exemplo, que jovens muçulmanas sejam mortas pelos pais porque namoram. Os direitos teriam que prevalecer sobre a religião.

\section{Contribuições brasileiras}

As principais contribuições brasileiras ao Programa de Ação do Cairo das quais tenho conhecimento direto foram:

- exemplo de envolvimento de organizações da sociedade civil, especialmente de mulheres, e associações científicas;

- todos os direitos humanos para todos os migrantes internacionais;

- uma definição dos princípios que permitiu o consenso de todos os países presentes na conferência, com respeito pleno aos valores religiosos e éticos, de um lado, e o pluralismo, de outro;

- eliminação de toda e qualquer justificativa malthusiana, inclusive quanto a "ameaças" ao meio ambiente da população e da pobreza;

- convencimento da China de não descartar o desenvolvimento sustentável em nome do direito ao desenvolvimento;

- aborto em casos e circunstâncias em que não esteja contra a lei, já que a linguagem de "aborto legal” era inadmissível. Foi um jeitinho brasileiro; 
- promoção da reunificação familiar, sem estabelecer um direito que justificaria a migração internacional sem limites;

- maior atenção para a necessidade de informação técnica, que a academia e associações científicas podem oferecer.

\section{Conclusões}

O Programa de Ação do Cairo foi uma nova síntese comparável àquela tornada oficial na Rio-92, quando o desenvolvimento sustentável foi consagrado como uma combinação de desenvolvimento e ambientalismo. A saúde e os direitos reprodutivos e sexuais foram uma nova síntese entre o planejamento familiar e o feminismo, até então considerados incompatíveis.

Neste caso, o Brasil brilhou. Só foi elogiado, nunca criticado, ao menos abertamente, enquanto ouvi críticas de todos os outros países que se manifestaram. Foi um desempenho notável, colocando o Brasil num papel de liderança global.

Nas negociações internacionais, é fundamental o conhecimento dos assuntos em pauta e de quem é quem, considerando os elementos técnicos e políticos, como também é essencial o domínio do inglês.

0 consenso foi facilitado pelo fim da guerra fria. Pelo menos a pressão aplicada ao Egito pelos Estados Unidos, ainda uma superpotência, resultou em algo muito positivo. As superpotências podem servir para fins além da dominação e exploração.

As pessoas que realmente entendem o que diz o documento e o que significa podem ser contados nos dedos. A maioria focaliza um ponto ou outro, sem perceber as inter-relações entre as partes.

Ainda cabe discussão sobre o conceito de direitos. Para alguns, quem tem um direito ferido ganha na justiça. Para outros, os direitos são aspiracionais. Ocorre uma multiplicação de direitos de todos os tipos, nem sempre compatíveis entre si, inclusive para grupos específicos, não apenas seres humanos ou cidadãos.

Cabe analisar os diversos acordos internacionais sobre assuntos econômicos, sociais e ambientais, inclusive clima, biodiversidade e desertificação, os quais geram implicações concretas mais fortes do que os assuntos acordados no Cairo. Hoje em dia, a abordagem mudou de programas de ação para objetivos de desenvolvimento sustentável. Qual a efetividade? Quais os indicadores?

Outros assuntos que não receberam a devida atenção no Cairo incluem gênero, juventude, envelhecimento, medicalização, fundamentalismo, crescimento diferencial entre países e migração internacional. 


\section{Referências}

ABEP; UNFPA. Brasil, 15 anos após a Conferência do Cairo. Campinas: Associação Brasileira de Estudos Populacionais, United Nations Population Fund, 2009.

ALVES, J. E. D. População, desenvolvimento e sustentabilidade: perspectivas para a CIPD pós2014. Revista Brasileira de Estudos de População, v. 31, n. 1, p. 219-230, 2017.

PATRIOTA, T. Relatório da Conferência Internacional sobre População e Desenvolvimento: plataforma do Cairo, 1994. In: FROSSARD, H. (org.). Instrumentos internacionais de direitos das mulheres. Brasília: Secretaria Especial de Políticas para as Mulheres, 2006. p. 33-137.

RUBARTH, E. A Conferência Internacional sobre População e Desenvolvimento. Brasília: Divisão das Nações Unidas, Ministério das Relações Exteriores, 1994.

SAWYER, D. População e desenvolvimento sustentável: encontros e desencontros internacionais. Brasília: Instituto Sociedade, População e Natureza, 2019.

UNITED NATIONS. Report of the International Conference on Population and Development, Cairo, 5-13 September 1994. New York: United Nations, 1994. (Publication E.95.XIII.18).

WONG, L. R.; ALVES, J. E. D.; VIGNOLI, J. R.; TURRA, C. M. (org.). Cairo+20: perspectivas da agenda de população e desenvolvimento sustentável pós-2014. Rio de Janeiro: Asociación Latinoamericana de Población, 2014.

\section{Sobre 0 autor}

Donald Sawyer é Ph.D. em Sociologia pela Universidade de Harvard. Assessor sênior no Instituto Sociedade, População e Natureza (ISPN).

\section{Endereço para correspondência}

SHCGN CLR, Quadra 709, Bloco E, Loja 38 70750-515 - Brasília-DF, Brasil 